dr. Nena Mijoč

Filozofska

fakulteta

$v$ Ljubljani

\section{ODRASLI SE UČIMO \\ Z DELOVANJEM}

Izkušnje so bistvo učenja
$\mathbf{N}$

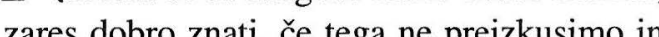
ne izpopolnjujemo v praksi. To velja za najbolj enostavna opravila in spretnosti, na primer vožnjo s kolesom, in tudi za najzahtevnejše procese umetniškega ustvarjanja ali kritičnega razmišljanja. Izkušnja je srž učenja, kot meni že J. Dewey. Tako je videti, da se predvsem odrasli učijo $\mathrm{z}$ delovanjem, otroci pa z izobraževanjem. Vendar sta tudi izobraževanje in teoretični študij neka vrsta delovanja, spretnost in umetnost, s katero se srečamo najprej med šolanjem in se kasneje pod vplivom izkušenj spreminja vse življenje.

\section{UČENIE KOT PROGRESIVNO SPREMINJANJE NA TEMELJU IZKUUŠEN]}

Ne samo odrasli, vsi se učimo $z$ delovanjem. $\mathrm{Na}$ to, kako razmišljamo, kako se učimo, in kako delujemo, vplivajo naše delovanje iz

Sodobno pojmovanje učenja pomeni predvsem interpretacijo izkušenj. preteklosti, naše izkušnje in naša interpretacija izkušenj. Tudi otroci se učijo $z$ delovanjem, vendar je njihovo delovanje prepogosto omejeno predvsem na šolske izkušnje, pri čemer sprejemajo znanja in informacije zgolj na površinski ravni, kot dejstva, ki jih ne povežejo s svojimi izkušnjami. Tako jih šola, če zanemari in jim ne pomaga interpretirati njihove izkušnje, uči, da učenje pomeni sprejemanje in reprodukcijo informacij. S tem lahko dobijo »napačno razlago« učenja: da je učenje zgolj kopičenje informacij in spoznanj, ki niso povezane $\mathrm{z}$ življenjem. Tako začnejo oboje razlikovati in sprejmejo mnenje, da sta teorija in objektivno znanje nekaj povsem drugega kot življenje in delo. $S$ tem se mnogi mladi naučijo gledati na znanje in na učenje kot na nekaj, kar spada v šolo, ni pa zelo uporabno v življenju. Takšno površinsko gledanje na znanje in površinsko učenje imenuje Usher »anekdotsko učenje (Usher, 1985). Torej so vsakdanje izkušnje le anekdote, ki jih slabo povezujejo med seboj, iz katerih se ni moč kaj dosti naučiti, posameznik jih ne poveže s teoretičnim znanjem. To pojmovanje daje napačen vtis, da se učimo samo v šolah, kasneje pa morda še na tečajih, seminarjih in $\mathrm{v}$ učnih delavnicah.

Vendar se odrasli, ki imajo tudi delovne izkušnje, natančno zavedajo, kako intenzivno so se spreminjali, prilagajali in učili, ko so začeli opravljati določeno delo, pa tudi kasneje, ko so svoje delovno področje morda spremenili. Učenje ni potekalo zgolj kot priprava na delo, temveč tudi neposredno med dejavnostjo samo. Čeprav se lahko določenih opravil naučimo z opazovanjem in posnemanjem, bomo tako pridobili le spretnost za določeno dejavnost. To bomo znali opravljati, ne bomo pa znali razložiti (ali pa bo težko povedati), kako se ta opravlja. Za nepredvidene okoliščine ne bomo pripravljeni. Imeli bomo zgolj »vedenje v dejavnosti«, ne pa tudi znanja. Šele zah- 
tevnejša dejavnost, ki ni vselej popolnoma enaka, zahteva razmislek. Pogosto sprožijo netipični primeri v praksi nove dileme, ki jih je treba na novo opredeliti in imenovati. Šele razmišljanje ob dejavnosti (reflection-in-action, Schon 1983) omogoča pretvarjanje praktičnih izkušenj v spoznanja, ki so verbalizirana in med seboj povezana znanja.

Tudi ljudje z bogatimi življenjskimi izkušnjami bodo vedeli, kako veliko so se naučili pri reševanju vsakdanjih življenjskih problemov, ko so spremenili svoje življenjsko okolje, ko so se preselili v drugo kulturo. Pogosto ni šlo zgolj za prilagajanje okolju, za socializacijo ali za naključno učenje, temveč za zavestno prizadevanje in bolj ali manj načrtovane poti osvajanja novih potrebnih znanj, spretnosti ali navad. Učili so se torej s samostojnim izobraževanjem.

Mnogi odrasli so se morali še pred začetkom dela dopolnilno izobraževati, se specializirati, poglobiti svoje znanje bodisi na različnih tečajih, seminarjih ali pa s samostojnim izobraževanjem (morda $\mathrm{z}$ načrtnim opazovanjem delovnega procesa, mentorskim sodelovanjem, študijem literature).

Šele globlje razumevanje učenja kot progresivnega spreminjanja človeka na temelju izkušenj, zavedanje, da nas spreminjajo lastne izkušnje, in interpretacija izkušenj omogočajo učinkovitejše učenje v življenju. Podobno poudarja Sandra Cuzack, da je učenje predvsem osmišljanje izkušenj (Cusack, 1991).

\section{POMEMBNA JE POVEZANOST MED TEORIJO IN PRAKSO}

»Zares, razlaganje brez namena spreminjanja je prazno, sprememba brez razlage je slepa. Razlaganje in sprememba, teorija in praksa nista dva razdvojena dejavnika, ki ju je moč kombinirati, medsebojno se prepletata tako, da se znanje oplaja s prakso, prakso pa vodi
Ljudje se v življenju največ naučimo z izkušnjami. Določene razlage, tudi interpretacije in teorije, lahko sprejmemo kot pravilne, vendar vanje verjamemo šele, ko nam jih potrdijo izkušnje. Seveda je možno tudi nasprotno, da slepo verjamemo v interpretacije, ki se v praksi ne potrjujejo, da se oklepamo razlag, ki so daleč od resničnosti. Takšno zaprto gledanje na zunanjo resničnost pa nam zapira nadaljnjo pot spoznavanja stvarnosti in učenja.

znanje, oboje, teorija in praksa spremenita svojo naravo, ko prenehata biti razdvojeni.« (Fromm, str. 143)

\section{PREOHLAPNA POVEZAVA MED TEORIJO IN PRAKSO}

$\mathrm{Z}$ raziskavo o izkustvenem učenju odraslih (Mijoč, 1995) smo ugotovili negativen odnos do teorije in šole tudi zaradi negativnih izkušenj s šolo, predvsem pri odraslih brez poklicne izobrazbe. Intervjuvani P. Ž. (40 let, zaposlen, osnovna šola) verjame, da se $\mathrm{v}$ šoli ni ničesar naučil, in pozablja, da si je vendarle pridobil osnovne spretnosti, kot so znanja pisanja, branja in računanja, brez katerih $\mathrm{v}$ današnjem svetu ne bi mogel živeti in si kasneje pridobiti usposobljenosti za delo. Ceni predvsem delo in praktične spretnosti, ki mu pomagajo, da se lahko preživlja. Podobno dokazujejo odgovori na vprašanja, katero znanje se zdi odraslim potrebnejše, praktično ali teoretično. Več kot polovica odraslih daje prednost praktičnim znanjem, odstotek takšnih odgovorov pa se zmanjšuje $\mathrm{z}$ višanjem stopnje izobrazbe respondentov (Delo, 26. 10. 1998, Delova anketa Koliko se učimo odrasli, $\mathrm{N}=545$ ).

Odrasli, ki so končali vsaj štiriletno srednjo šolo, bolj cenijo teoretična znanja in kot vir znanja tudi pogosteje uporabljajo strokovno literaturo (Mijoč, 1995). Na znanje pa drugače gledajo samouki, inovatorji in ljudje, ki so se do mnogih pomembnih spoznanj dokopali 


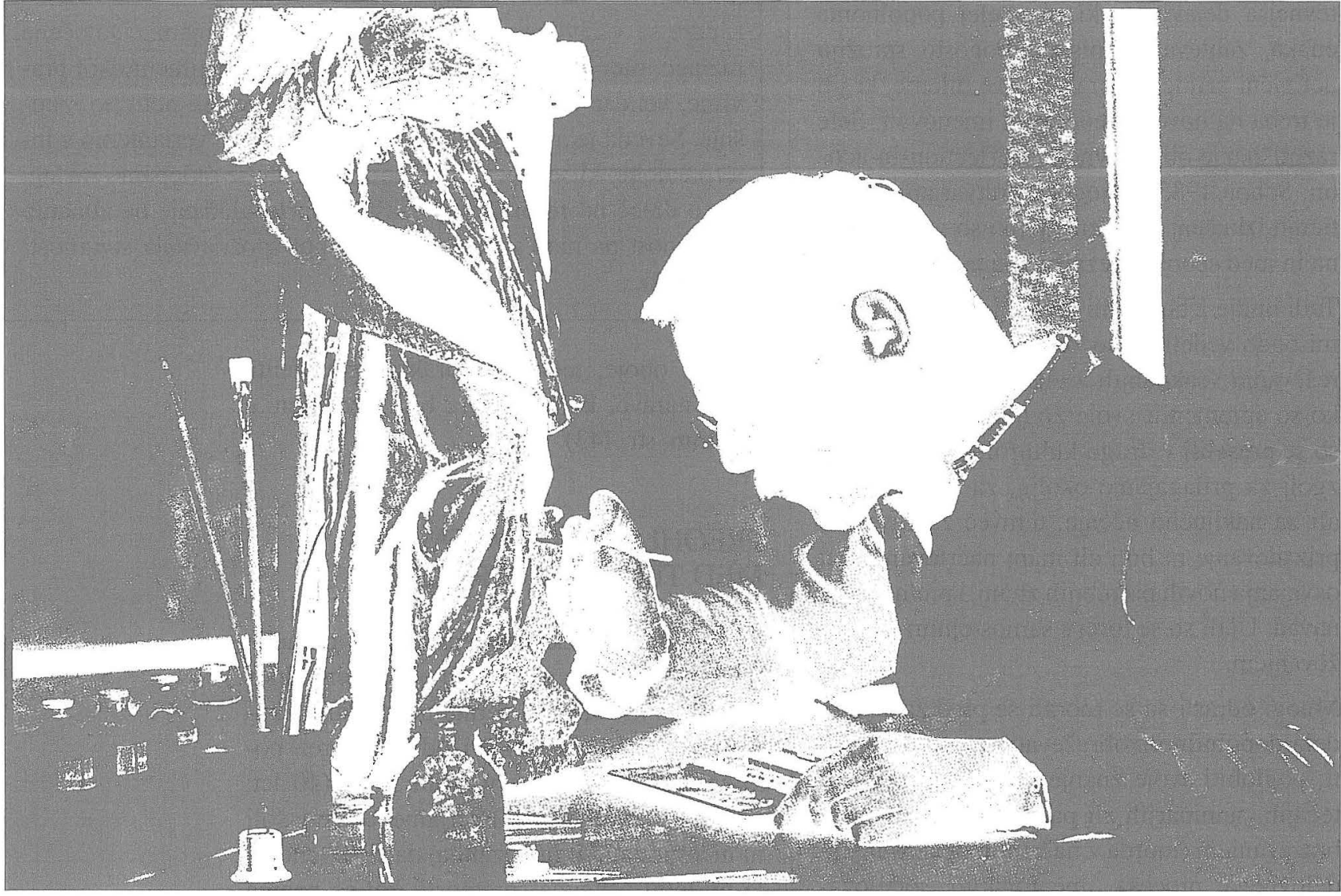

z izkustvenim učenjem ali samostojnim študijem. Izkušnje in življenjski problemi so bili zanje izziv, spodbuda, da so segli tudi po »objektivnem znanju«, da so si razložili svoje izkušnje in jih povezali s širšimi spoznanji ter teorijo.

\section{Teorija nam pomaga izkušnje spremeniti $v$ nova spoznanja.}

$\mathrm{Z}$ raziskavo o izkustvenem učenju odraslih (Mijoč, 1995) smo ugotavljali, kako so se odrasli iz različnih družbenih slojev učili svoje dejavnosti. $\mathrm{Na}$ nadpovprečen uspeh posameznika v specifični dejavnosti so nas opozorili ljudje v podjetjih in lokalnem okolju. To so potrdili tudi posamezni intervjuvanci, potem ko smo jih o tem povprašali. Torej gre za izbrano populacijo uspešnih posameznikov vseh izobrazbenih stopenj. Od skupaj šestdesetih intervjuvancev je kar 59 intervjuvanih poudarilo, da so pri svojem delu uporabljali kot pomemben vir znanja tudi knjige ali strokovne priročnike. Nekateri med njimi, tisti, ki so dosegli vsaj osnovnošolsko izobrazbo ali manj, so vztrajali pri uporabi tiskanih virov, čeprav so nam priznali, da »slabo berejo«. Zanimivo pa je, da so pri svojem učenju nekateri uporabili tudi zelo netradicionalne pristope. Na primer povečevalno steklo, čeprav ni šlo za probleme $\mathrm{v}$ zvezi $\mathrm{z}$ vidom. Tako si je U. M. (65 let, v pokoju) olajšal branje in ga napravil zanimivejšega. Ko je hotel izvedeti več o sadjarstvu, je dalj časa »nadlegoval« znance ter strokovnjake $\mathrm{z}$ različnimi vprašanji. Nato pa se le je odločil, da bo kljub pomanjkljivi pismenosti sam vzel v roke priročnike in se dokopal do odgovorov ter razlag na svoja vprašanja.

Posamezniki, ki so bili uspešni v določeni de- 
javnosti, so torej svoje izkušnje zavestno analizirali, probleme so spremenili v vprašanja, na osnovi vprašanj se je oblikovala želja najti odgovore ne le z preizkušanjem, temveč tudi $\mathrm{z}$ uporabo teoretičnih razlag iz strokovne literature. Praksa sama po sebi še ne pomeni izkušnje, izkušnje se spremenijo $\mathrm{v}$ nova spoznanja šele s teorijo. Praksa ne omogoča novih spoznanj, če o njej ne razmišljamo in je ne povežemo z znanji, teorijo in razmišljanjem drugih ljudi.

\section{ŽELJA IN ZAVESTNO ODLOČANJE}

John Dewey je med prvimi raziskoval pomen izkušenj za učenje. Pri konstrukciji teorije o učenju poudarja izkušnje, ki po njegovem mnenju pomenijo kontinuum, ki so odvisne od posameznika, ki ga po eni strani oblikujejo in vplivajo na prihodnje izkušnje. »Izkušnja je vselej to, kar obstaja zaradi transakcije med posameznikom in tistim, kar $\mathrm{v}$ določenem trenutku predstavlja okolje, bodisi drugi ljudje, igrače, orodja ali knjige ...« Vsaka izkušnja ne glede na našo željo ali namen živi naprej v naslednjih izkušnjah (Dewey, 38). Temeljni kategoriji izkušnje sta torej kontinuiteta in interakcija subjekta $\mathrm{z}$ zunanjim svetom. V teoretični razlagi izkustvenega učenja Dewey trdi, da se resnični namen vselej začne z impulzom (nagonom, strastjo, spodbudo, nagibom), ki ga ni mogoče takoj uresničiti, zato se porodi želja. V enostavnih okoliščinah se torej namen spremeni v dejanje (na primer narediti nekaj korakov do cilja), v zapletenejših pa začnemo opazovati objektivne možnosti. Šele opazovanje spremeni goli impulz v namen. O možnih posledicah lahko razmišljamo samo zaradi izkušenj, ki so bolj ali manj podobne sedanjim okoliščinam. Spreminjanje želje v namen ima torej več stopenj:

- opazovanje zunanjih možnosti;

- vedenje in znanje o tem, kaj se je v podobnih okoliščinah zgodilo v preteklosti (na osnovi lastnih izkušenj ali informacij, nasvetov drugih ljudi);

- presojanje, ki združi opazovanje in tisto znanje, ki ga lahko prikličemo in mu presodimo pomen.

Namen se razlikuje od osnovnega impulza ali želje tudi zato, ker gre za načrtovano aktivnost, ki upošteva možnosti in morebitne posledice.

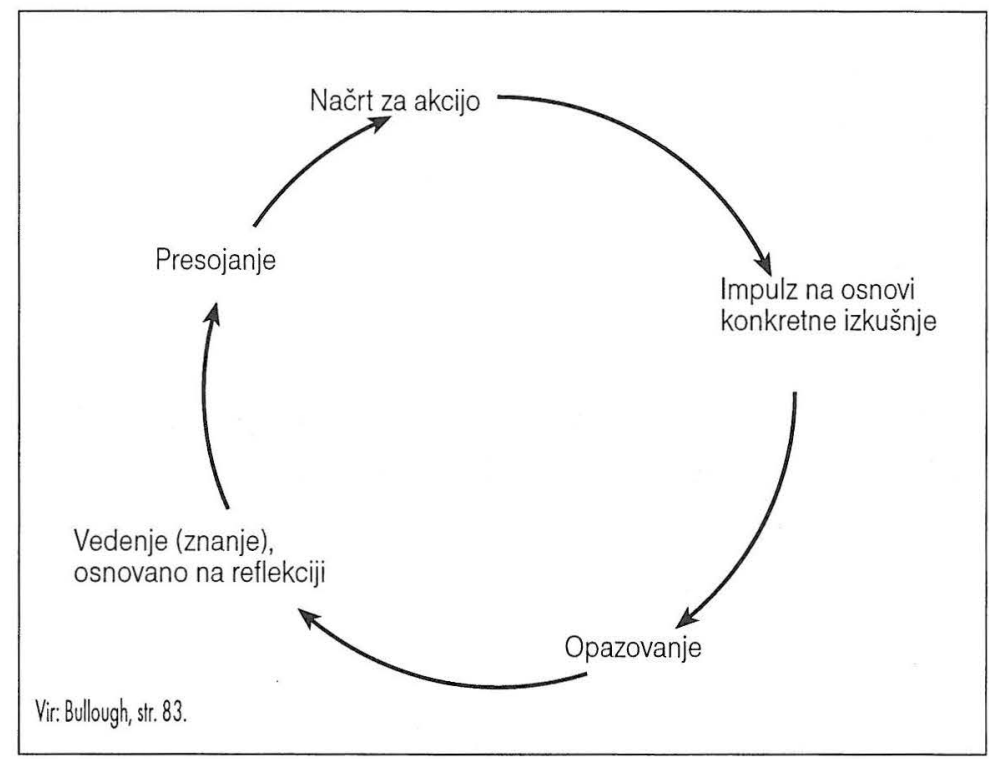

Tudi za vse intervjuvane osebe je bila značilna močna želja, da bi se z izbrano dejavnostjo aktivno ukvarjali. Večinoma je obstajala že na samem začetku ukvarjanja z dejavnostjo, pri nekaterih pa se je okrepila šele $\mathrm{z}$ dejavnostjo samo. Tako je na primer K. Š. začel izdelovati gobeline zato, ker je hotel dokončati gobelin, ki ga je začela njegova hči. Ko mu je to uspelo, pa je postalo izdelovanje gobelinov njegova najpriljubljenejša dejavnost $\mathrm{v}$ prostem času. V tehniki se je tako izpopolnil, da je imel več razstav v svojem okolju in da je »iznašel« popolnoma nov način »mešanja barv« Samo v enem primeru izmed šestdesetih je oseba pri intervjuvanju izjavila, da se ni želela ukvarjati z dejavnostjo, v kateri je bila kasneje zelo uspešna. »Z računalniki sem se začel ukvarjati, ker je to zanimalo sina, ker 
sem mu hotel zagotoviti enake možnosti, kot jih imajo drugi otroci. Prej sem menil, da se računalnika ne bom nikoli dotaknil, saj je bil zame tipični produkt stehniziranega sveta, «je pripovedoval B. J.

Zavestna odločitev za učenje nove dejavnosti je nujna za doseganje rezultatov.
Odločitev za to, da se bo oseba intenzivno posvečala določeni dejavnosti, je praviloma zavestna odločitev. »Zavestno odločanje pomeni zavestno reflektiran in zavestno kontroliran izbor med alternativami manifestnega obnašanja.« (Musek, 85)

Zavestna odločitev in zavestni nadzor nad dejavnostjo se manifestira v naslednjih dejanjih: izbirna dejanja, dejanja izpolnitve cilja, dejanja na podlagi zavestne odgovornosti in dolžnosti, dejanja zavestnega kljubovanja in dejanja na podlagi zavestnih hazardnih odločitev (isti avtor).

Pri analizi dejanj, povezanih z odločitvijo o intenzivnejšem ukvarjanju $\mathrm{z}$ dejavnostjo, smo ugotovili tele grozde značilnih situacij:

- situacije, povezane $\mathrm{z}$ razmišljanjem o lastnih interesih in možnostih (spremeniti način življenja, uresničevati svoje interese - 11 odgovorov);

- situacije v neformalnih skupinah (tekmovanje, prestiž, angažiranje, pripadnost - 10 odgovorov);

- situacije v družini (ustreči družinskim članom, izboljšati življenjske razmere v družini, razveseliti družinske člane - 10 odgovorov);

- situacije v službi (sprejemanje nalog, razvijanje novih nalog -10 odgovorov);

- eksistenčna negotovost (bivalni prostori, materialna eksistenca - 4 odgovori);

- drugo (sprejemanje odgovornosti za znano dejavnost, vključitev v tečaje, srečanja z zanimivimi osebami - 9 odgovorov).

\section{PREDANOST CILJEM IN USPEH IZOBRAŽEVANJA}

Odločitve so pogosto povezane $\mathrm{z}$ manifestnimi dejanji, kot je nakup pripomočkov in materiala za dejavnost, ali pa s sprejemanjem nalog in odgovornosti (v službi, obljuba prijatelju, dogovor o delitvi dela). Večina odločitev pomeni spremembo dejavnosti, pogosto tudi spremembo navad. Tako se je na primer S. M. odločil, da se bo vsak dan vsaj pol ure pogovarjal $v$ tujem jeziku, ki se ga je namenil samostojno naučiti. Navade vsakdanjega življenja pri drugih ljudeh so se spreminjale manj načrtno, nekako samodejno, ko so spremenili delovno področje ali pa svoje dejavnosti v prostem času.

Predanost cilju, ki smo ga sprejeli od zunaj, bo večja, če je cilj zastavil človek, ki ga imamo za avtoriteto, v katerega zaupamo in ki zna ugotoviti ter razložiti, v čem je tudi naš interes, da bi cilj dosegli. To spoznanje je posebej pomembno za učenje, ki ga vodi druga oseba, na primer mentor.

Vsako dejavnost vodijo zavestni ali manj zavestno zastavljeni cilji. Cilji delujejo z močjo privlačnosti in imajo glede na to neposreden vpliv na uspešnost, na motive pa gledamo kot na tisti dejavnik, ki dejavnost vzdržuje in spodbuja. Med samo dejavnostjo se privlačnost ciljev lahko tudi spreminja. Močno privlačnost, ki izpodrine druge manj pomembne cilje, $z$ drugo besedo imenujemo predanost. Predanost cilju pomeni najprej sprejemanje cilja, tesno povezanost z njim in odločenost, da ga dosežemo. Locke razlikuje tri stopnje predanosti (Locke, 1991, str. 138):

- privolitev (kljub morebitnemu osebnemu nestrinjanju),

- identifikacija (s ciljem se strinjamo, ker imamo radi osebo, ki ga je zastavila),

- internalizacija (strinjamo se, ker se osebno zavzemamo za cilj). 
Pomembno je, da je oseba, ki je izbrala cilj, tudi fizično dostopna, da je podpirajoča in vredna zaupanja. Cilj mora znati prepričljivo razložiti in uporabljati razumno mero pritiska. Zaupanje v avtoriteto je večje, kadar je oseba kompetentna, kadar veliko ve in jo imajo drugi ljudje radi. Kadar so naloge prelahke, bodo predani ljudje slabše uresničili zadano nalogo od tistih z manjšo predanostjo. Pri zahtevnih nalogah pa je ravno nasprotno: zelo predani ljudje bodo dosegali boljše uspehe od tistih z majhno predanostjo. Za ljudi, ki so zelo predani določenim ciljem, je značilno, da se njihovi osebni cilji prekrivajo s širšimi cilji, s cilji in nalogami, ki so jim bile dodeljene. Učinkovitost oziroma uspešnost doseganja dodeljenih ciljev se poveča, če oseba, ki je cilje dodelila, velja za legitimno osebo. Dodatno vpliva na uspešnost informacija o pozitivnem učinku in nagrada ali kazen. Kadar doseganje cilja daje tudi dobro normativno informacijo (skladnost z normami, vrednotami, zakonom), kadar omogoča občutek dosežka, kadar zagotavlja samoizpopolnjevanje in pomeni posamezniku dovolj velik izziv, je več možnosti, da bodo tudi dodeljeni (torej v osnovi od zunaj zastavljeni) cilji doseženi. Kadar so osebni cilji del skupinskih ciljev, to povečuje predanost.

Večina intervjuvanih oseb, ki so bile pri svojih projektih izkustvenega učenja izjemno uspešne, so imele načrt, kako doseči cilj, ki so si ga zastavile. Vendar ni bil vselej natančno vnaprej pripravljen, oblikoval se je postopoma, ko so svojo dejavnost začeli opravljati z vse večjo predanostjo. Izmed šestdeset intervjuvanih oseb jih je na začetku imelo konkreten in jasen cilj le 24 , kasneje, po določenem času, pa že 45. Druge so imele pred seboj cilj čim bolje napraviti to, kar zmorejo. Mnoge so med samo dejavnostjo spoznavale ustrezne postopke dela, se učile s poskusi in na svojih lastnih napakah.

Niso se obremenjevale s tako imenovanim pristopom »tehnične racionalnosti «, ki vidi profe- sionalno aktivnost le kot tehnični problem izpeljave in aplikacije znanstveno dognane teorije in tehnike. Na osnovi tega vidika so raziskovanje, izobraževanje in praksa strogo ločeni. Raziskovanje naj bi dalo odgovore in tehnike za diagnozo ter reševanje problemov $\mathrm{v}$ praksi, praksa ponuja probleme za raziskovanje, izobraževanje pa temeljno, aplikativno in metodično znanje za uporabo v praksi (Schon, 1983).

Največji problem v praksi ni le, kako reševati tipične probleme, temveé kako odkriti in imenovati nove probleme v svetu nestabilnosti in negotovosti. Reševanje novih, nepredvidlivih problemov zahteva veliko strokovnost in pogosto tudi hitro odloćanje, ko stvari niso vnaprej predvidljive. To pa zmorejo le izkušeni in dobro teoretično izobraženi strokovnjaki. Tako težišče izobraževanja in izpopolnjevanja strokovnjakov, pa tudi drugih odraslih, ni več na izbiri pravih vsebin in pravih metod za izbrane clijne skupine, temveč se naloge v izobraževanju odraslih vse boli pomikajo k omogočanju učenja posamezniku.

Pomembno postaja spoznanje, da so poti učenja raznolike in individualne, pogosto prav nič podobne šolanju. Naloge izobraževalcev se prevesijo torej v približevanje izobraževalnih možnosti čim večjemu številu ljudi, v najrazličnejših življenjskih in delovnih okoliščinah. Med pomembne nove možnosti bi lahko šteli središča za samostojno učenje v podjetjih, knjižnicah, izobraževalnih institucijah in drugje, najrazličnejše delavnice ob razstavah, sejmih in drugih prireditvah ter v najrazličnejših okoljih, možnosti za učenje v študijskih krožkih, informacijska središča z dostopom do virov znanja ipd. Hkrati pa se s tem povečujejo potrebe po svetovanju in pomoči odraslim, ko si pripravljajo svoj individualni izobraževalni načrt in s svetovanjem izbirajo najustreznejše poti izobraževanja.

\section{SKLEPNE MISLI}

Po mnenju Jansena in Van der Veena (992) bomo morali v izobraževanju odraslih upoštevati tudi globalne spremembe v družbi. Avtor- 
ja se opirata na sociološko teorijo Ulricha Becka, ki meni, da se vse bolj približujemo obdobju transformacije družbe iz enostavne sodobne družbe $\mathrm{v}$ razmišljujočo sodobno družbo. Ta je zasnovana na konceptu rizične družbe, v kateri so konsekvence znanstvenih spoznanj in novih tehnologij nepredvidljive, pri čemer se srečujemo s problemi ekološke (ne)varnosti, potrebo po vse večji mobilnosti delovne sile (brezposelnost), problemi distribucije politične moči in drugimi globalnimi vprašanji. Vse to postavlja nove zahteve po globalnih temah v izobraževanju odraslih. Vendar novih tem ne bomo mogli »prenašati« na odrasle s klasičnimi metodami. Tako je na primer ekološko izobraževanje, ki je razlagalo raznolike možnosti za ekološki propad, preveč razorožilo in destimuliralo ljudi za nadaljnje učenje in delovanje. Tudi kvaliteta življenja je namreč v rizični družbi močno ogrožena. Av-

Sodobna razmišljajoča družba je lahko le kombinacija izkušenj in teoretičnih znanj torja za nove teme predlagata povezovanje ljudi v skupine. Ti se povezujejo zaradi problema, ki ga ugotavljajo. Namesto skupinskega »izkustvenega učenja« predlagata »pogovore o prihodnosti $\ll$. Tu ne gre za izkustvo tu in sedaj, temveč za kritično razmišljanje in dialog $\mathrm{v}$ skupini o tem, kako živimo svoje vsakdanje življenje in kako je to življenje povezano $\mathrm{z}$ globalnimi nevarnostmi, ki jih pogosto ni moč občutiti na podlagi lastnih izkušenj. Po dobi popularnega »izkustvenega učenja«, ugotavljata, se vse bolj uveljavlja upravičena potreba po kombinaciji teoretičnih znanj in izkustveno pridobljenega znanja. Nova, rizična družba je zaznamovana $z$ vse večjo individualizacijo človeka, ki po eni strani ogroža demokratično politično delovanje, po drugi strani pa je pogoj za demokratizacijo družbe, v kateri so šele svobodni posamezniki sposobni enakopravnega demokratičnega delovanja. Zato so družbene organizacije, ki podpirajo civilno družbo, vse pomembnejše za kritični dialog s centri politične in ekonomske moči. Znotraj njih se oblikuje skupnostno izobraževanje, ki ni vnaprej tematsko trdno določeno in načrtovano, temveč omogoča tudi medsebojno komunikacijo o pomembnih temah in poteh za kritično razmišljanje. Šele tako bo izobraževanje odraslih postalo prostor za diskusijo o družbenem razvoju in njegovem vplivu na osebno ter družbeno življenje. Pomembneje kot razlaganje splošnih idej in teorij bo, da bo izobraževanje odraslih spodbujalo in sprožalo pri ljudeh razmišljanje o vprašanjih eksistence, socialnem in kulturnem razvoju ter krepilo njihovo moč za odločanje in akcijo.

\section{LITERATURA}

Bullough, M.: A Consideration of Some Models of the Learning Process: Studies in the Education of Adults, NIACE, England, 1989.

Cusack, A. Sandra: Making Meaning from Experience: Journal of Educational Gerontology, Vol. 6, No. 1, UK, 1991.

Daloz, L. A.: Effective Teaching and Mentoring, JosseyBass, San Francisco, 1986.

Dewey, John, Experience and Education, The Macmillian Company, 1956.

Fromm, Erich: S onu stranu okova iluzije, Naprijed, Zagreb, 1984, str. 143.

Jarvis, Peter: Ethics and education for adults in the late modern society, NIACE, England and Wales, 1997.

Jansen, Theo, Van der Veen, Ruud: Reflexive modernity, self-reflective biographies: Adult education in the light of the risk society, International Journal of Lifelong Education, No. 4, Taylor \& Francis, London, 1992.

Locke, Edwin J. A., Latham Gary P.: A Theory of Goal Setting and Tasks Performance, Prentice Hall, New Jersey, 1990.

Mijoč, Nena: Izkustveno učenje odraslih in sociokulturni sloj, doktorska disertacija, Ljubljana, 1995.

Musek, J.: Narava in determinante zavestnega odločanja, Filozofska fakulteta, Ljubljana, 1985.

Schon, Donald A.: The Reflective Practitioner: How Proffesionals Think in Action, New York, Basic Books, 1983.

Usher, R. S.: Beyond the Anecdotal: Adult Learning and the Use of Experience. V: Studies in the Education of Adults, Vol. 17, No. 1, NIACE, UK, 1985. 